\title{
THE RECONSTRUCTION OF THE PLANT OF THE CHICAGO BOARD OF TRADE.
}

\author{
BY BION J. ARNOLD.
}

When the writer agreed some four weeks ago to prepare a paper on the reconstruction of the plant in question, he hoped to be able to present to the Institure to day some records of its operation, or data which would be of value, but owing to the delay in the arrival of certain parts of the plant, the question of operating it a sufficient length of time to secure such data proved impracticable, and not wishing to appear before this body with any data the completion of which did not extend over a sufficient length of time to make it reliable, he must confine himself to-day practically to a description of the plant, with the expectation of presenting to this Instritute at a later date the records of its operation, in a form which he hopes will be of some permanent value. The plant involves a number of departures from the standard lines of office building engineering, and if the results of its operation are as successful as it now seems they will be after running a short period, the annual expenses of the operation of the plant will be reduced from $\$ 25,000$ to $\$ 15,000$, consequently its operation will be watched closely by those who have the matter immediately in charge.

The writer believes that all the energy required to produce motion and light in an office building should be developed in one set of steam engine cylinders and on one generator, having, of course, one set of cylinders and their generator in reserve. This set of cylinders, together with the working parts of the engine and its generator connected directly to it, constitute the unit which produces the energy of the plant, and this unit should be made to 
work at its maximum economical load throughout its entire period of operation, while the energy from the unit should all be utilized during its running time. Having this idea constantly in view, the designer of this plant has planned to follow it out as closely as possible.

The old plant consisted originally of six horizontal tubular boilers operating at a steam pressure of about 75 to 80 pounds, and driving five small steam engines distributed in different

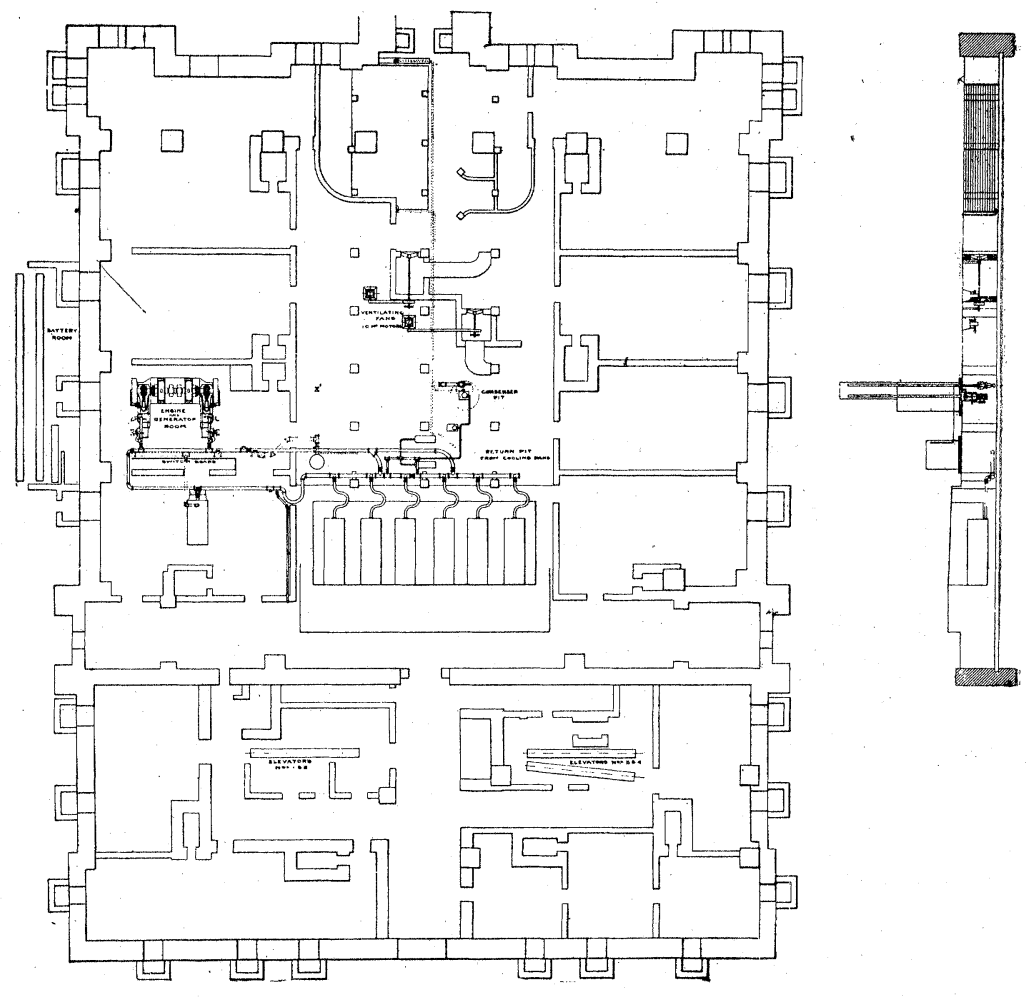

FIG. 1.

parts of the building, together with the necessary steam pumps, air compressors, etc, used for feeding the boilers, and operating the hydraulic elevators. Two of these engines were belted to a line shaft and drove several small incandescent and are dynamos for lighting the building. The three other engines were used for driving the ventilating fans, three of which were located in the attic and two in the basement, and were driven by the engine by means of rope-drives with sheaves and ropes running at various 
angles throughout the building. The elevators were driven by two horizontal compound direct-acting pumps, which consumed from 80 to 100 pounds of water per horse-power of energy delivered to the elevator cars. It became apparent after an examination of the plant that if the steam pressure could be increased to 125 pounds per square inch, so as to get the advantage of drier steam, and all the pumps in the plant which were consuming steam full stroke eliminated, and the energy of the plant produced by a compound condensing engine running at an economical load, that a large reduction in the operating expenses of the plant could be effected. The old boilers having been in use for about nine years, were almost ready to be condemned by the boiler inspectors, consequently it was an easy matter to decide upon replacing the boilers with heavier ones which would work at the above pressure. The adoption of a compound condensing engine to work under this increased steam pressure was a natural sequence which enabled the energy to be produced with the least possible coal consumption. After quite an extended investigation it was decided to supplant the hydraulic elevators with horizontal screw multiple sheave elevators, as the investigation showed that these machines could be operated for considerable less money per car mile than the hydraulic machines, under the conditions which existed in this plant. The operation of these elevators in practice has fully proven the correctness of this position. They have been in operation about four months now, on an average consumption of $4 \frac{1}{4}$ kilowatt-hours per car mile, and as the duty required of them is exceptionally heavy, and the cars. very large, this showing is very satisfactory.

The general plan of the plant is as follows:

Referring to Fig. 1, which represents the basement of the Chicago Board of Trade, the relative location of the different. machines which enter into the plant can be determined. It will be seen that the installation consists of the following:-Five $66 \mathrm{x}$ $16 \mathrm{ft}$. horizontal tubular boilers, designed to carry 125 pounds pressure per square inch; two $150 \mathrm{H}$. P. horizontal compound condensing engines running at 275 revolutions per minute, each directly connected to a $75 \mathrm{~K}$. w. direct current generator, under a special system hereinafter described, which permits of either or both generators being driven from either engine. Four horizontal 30 н. P. multiple sheave elevators; six 10 H. P. electric motors, five of which operate ventilating fans, and one the machinery in 
the machine shop, 50-2000 c. P. constant potential are lamps and 600-16 c. P. incandescent or glow lamps. There are also sixtyfive 1600 ampere-hour storage cells, and the necessary switchboard and connections for the handling of the above machinery, all of which is more distinctly described hereafter. One of the compound steam pumps has been retained in order to keep the tank on the roof of the building supplied with water for use in the wash-basins, closets, etc. It may prove advantageous in the future to substitute for this an electrically driven pump, but

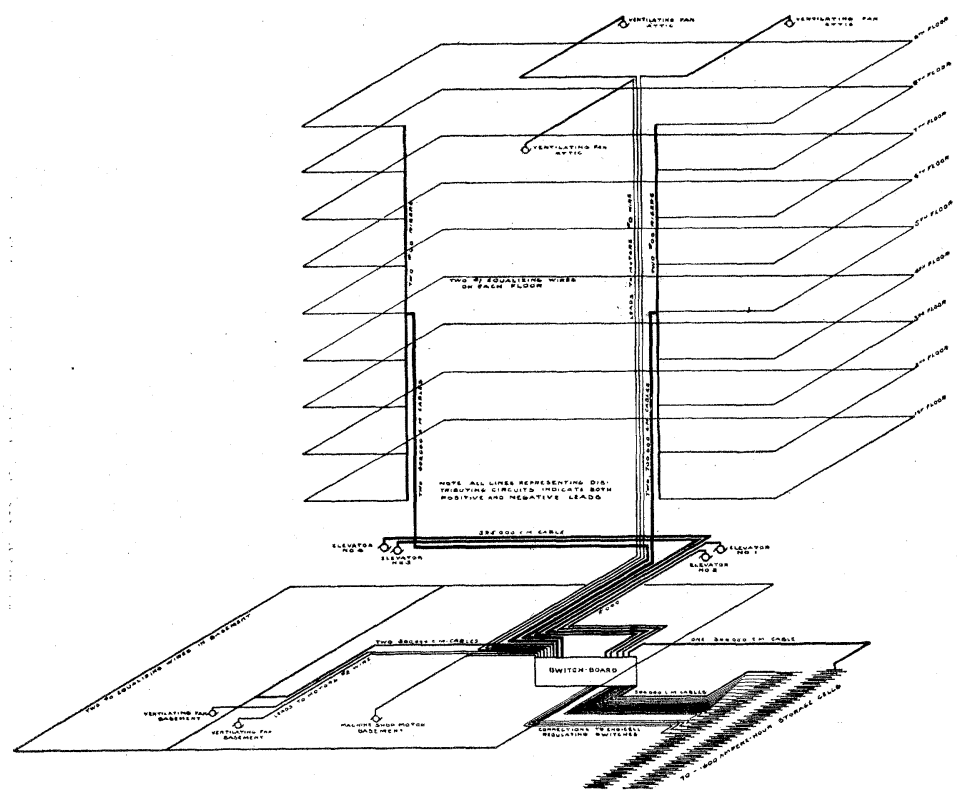

FIG. 2.

it has been thought best not to discard the old one at present, inasmuch as it is already on hand.

Fig. 2 represents diagrammatically the main leads or copper conductors of the building, used for the operation of the above described electrical machinery. The general plan is clearly shown by the diagram, and this system was adopted owing to the fact that the building was so constructed that two main flues or passageways extending from the basement to the attic, in opposite portions of the building, and near its centres, were available for carrying the main risers. It was decided to place in these passageways vertical risers of sufficient carrying capacity to conduct 
the total amount of energy required for the nine floors, and to join the floor leads or secondary mains onto each of these risers at their ends. With this arrangement it was possible to feed the secondary mains at two independent points, thus equalizing the pressure to better advantage and making the plant more reliable in operation. From the centre of these vertical risers, or at about the fifth floor, the main leads drop down each shaft, thence extend horizontally on the ceiling of the basement to the switchboard. Each of these mains leading to the centre of distribution in each shaft is of sufficient carrying capacity to carry the total load of the building, exclusive of the basement, consequently if a fuse blows on either one of the mains, or if by any accident one of the mains should become broken or opened, the other main will carry the necessary current and keep the lights operating in the building. This precaution was taken owing to the fact that business matters of great importance are transacted in this building, and the loss of a few minutes at certain times would be disastrous to the men who operate in the building, consequently every precaution for safety and reliability had to be taken.

The basement circuit is independent of the above described mains, and consists of positive and negative leads, surrounding the entire basement of the building, from which are tapped the are and incandescent lights used in the basement. The motor circuits are closely indicated in the diagram, and are independent of the lighting circuits, and are so planned that the starting rheostats of the motors are connected on the switchboard under the control of the engineer, thus making it possible for the engineer to start or stop any motor in the building without leaving the switchboard. The elevator circuits are also independent of the lighting and motor circuits, and it is possible to throw the current on or off any elevator at the switchboard. The batteries are located in a room adjoining the main engine room, and connected with the switchboard, as shown on the diagram.

The losses in wiring circuits of the building are computed as follows: Between generator and switchboard, one-half of one per cent.; between switchboard and centre of distribution, two and a half per cent.; from centre of distribution to secondary mains, one per cent.; between secondary mains and lights, one per cent.-making the total loss between generator terminals and lights five per cent. 


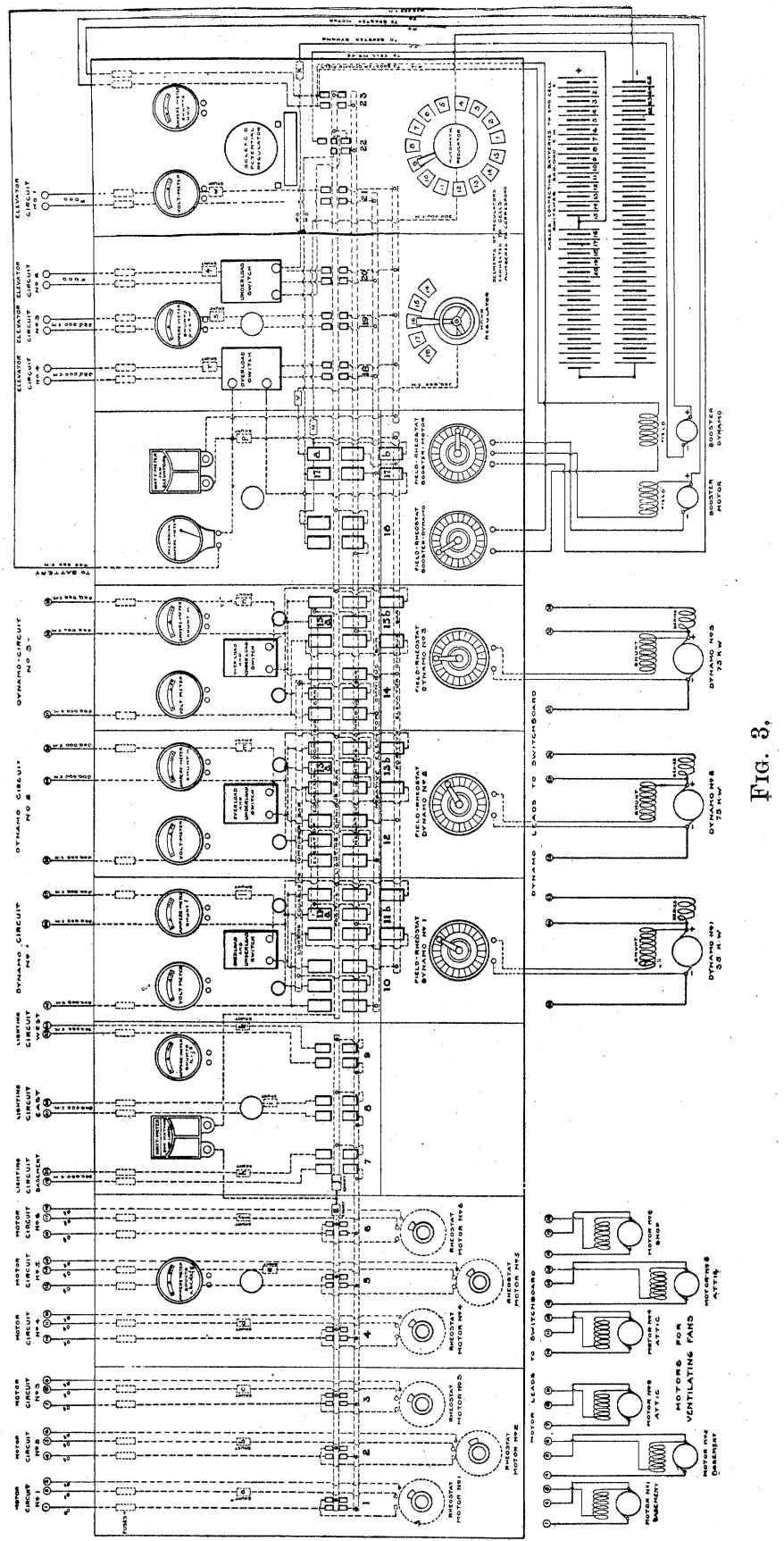


Fig. 3 represents largely diagrammatically the switchboard of the plant. From this it will be noticed that the plant is designed for three generators. but two of which are now in operation, as they are sufficient for the work. The lighting 'bus bars carry the main lighting circuits, controlled by switches 7,8 and 9 , and also the motor circuits controlled by switches $1,2,3,4,5$ and 6 . In the main lighting 'bus bar is placed a recording wattmeter, which registers all the energy delivered from the generator to the light and motor portions of the plant. In the elevator 'bus bars is placed another recording wattmeter, which registers all the energy delivered to the elevators from the lighting 'bus bars. With this arrangement and the means available in the plant for measuring the amount of coal and water consumed, the operators are enabled to keep accurate daily records of the cost per kilowatt of the energy produced and delivered by the plant. The diagram of the switchboard clearly shows the windings of the different generators and motors, and need not be further explained.

The generators are connected to the board by means of two switches, one of which is a triple-pole double-throw switch, and is arranged so that when thrown into the upper position it connects the generator to the elevator 'bus bar, using the compound winding of the generators. This arrangement permits the generator to operate the elevators and take care of the variable load without the use of the batteries. When the same switch, for instance No. 13 or 15 on the accompanying diagram, is thrown in its lower portion, the circuits are so arranged that the compound or series winding of the generator is cut out, and the equalizer connection from the generator becomes the positive connection, and the generator is connected to the elevator 'bus bars shunt wound, thus eliminating its series winding. With this arrangement, the generators and the batteries are run in multiple on the elevator load.

Referring now to the right-hand part of the board which is the storage battery portion proper, the operation is as follows: Under normal conditions, any elevator is operated shunt wound in parallel with the batteries by closing its corresponding switch, as, for instance, switch 15 for dyuamo No. 3. downward the $15 b$ position. By closing switch 17 to 17 a position, the current passes from the positive elevator 'bus bar to the hand regulating cell switch, and out to cell No.16, when the regulator is placed as shown 
on the diagram. From cell 16 the current passes through the series of cells coming out at the negative end, thence through the proper conductor to the recording ammeter, thence to the overload switch and down to the negative terminal of switch No. 17 a. It will now be seen that whatever number of batteries are being. operated in this series, are in parallel with the generator. The hand regulator is placed in the position indicated to enable the operator to cut in a sufficient number of cells in parallel with the generator, so that the cells will be constantly charging during the time of operation of the elevators, except at the temporary moments of overload caused by an excessive demand for current by the elevators. When this pull from the elevator occurs, the batteries respond and take the surplus load from the generator. With this arrangement, about fifty of the cells will be kept constantly charged, and in parallel with the elevators. In case the amount of current entering the cells is excessive between the intervals of heavy load on the elevators, the hand regulator is adjusted so as to cut in one or more cells until the current becomes reduced to the proper amount for the batteries; and, on the other hand, if the amount entering the cells is not enough to keep them properly charged, the hand regulator is adjusted so as to cut out a number of cells until the proper amount of current is reached. In the meantime, if the 15 end cells require charging, they are charged by means of the independent booster or motor generator in the manner hereinafter described. All the batteries can be operated in parallel with the generators when running shunt wound, in the same manner as they are used in conjunction with the elevator 'bus bars, by closing switch 17 downward to position $17 b$. The connections for same can be easily followed on the diagram.

In order to operate the batteries in parallel with both the lighting and the elevator 'bus bars at the same time and maintain a practically constant voltage on the lighting 'bus bars, it is necessary to operate the generators shunt-wound instead of compoundwound. As before shown, the switches are so arranged that the compound winding of the generators can be utilized when the batteries are not in service, and the shunt winding used when the batteries are being run in parallel with the elevators and lights. Therefore, to maintain a practically constant voltage on the lighting 'bus bars and to run the elevators in parallel with the batteries at the same time, the operation is as follows:-Switch $17 \alpha$ 
is closed upward and operates as previously described in conjunction with the elevators and batteries. Switches 10,12 and 14 are open to prevent the generators operating compound-wound on the lighting 'bus bars. Switch 16 is closed and the current passes as follows:-From the positive elevator 'bus bar through the switch $17 a$ to the centre of the hand regulating switch, thence through the connection from the hand regulating switch to the corresponding cell (shown on the drawing as cell 16) thence through the series of 49 cells, out through the negative end and its corresponding connection, through the recording ammeter and overload switch, to the negative side of switch $17 \alpha$, thence to the negative elevator 'bus bar. It should be borne in mind that the lighting 'bus bars and the elevator 'bus bars are operating at different potentials, and that the potential on the elevator 'bus bars is changing slightly with the change of load, caused by variable load on the elevators. When the demand for current from the cells is great, as for instance when the elevator load is severe, the E. M. F. of the number of cells in parallel with the elevators necessarily drops, consequently the E. M. F. of the number of cells in parallel with the lighting bars, which includes all the cells working with the elevators, and a few of the regulating cells, would correspondingly drop, and some means must be provided to hold up the voltage of the lighting 'bus burs. This is accomplished by means of the automatic regulator which is controlled by a solenoid switch, shown in the upper right hand portion of the diagram. This solenoid switch operates by means of suitable connections to the lighting 'bus bars, in such a manner as to make and break the circuit through mercury cups as follows:-When the voltage of the lighting 'bus hars is reduced slightly, one side of the field of a right and left hand motor is thrown in, which causes the arm of the automatic regulator to move clock-wise, thus cutting in more cells in parallel with the lighting 'bus bars and holding the E. M. F. up. When the E. M. F. of the lighting 'bus bars reaches its proper voltage and tends to exceed it, the solenoid acts in the opposite direction and cuts in the left hand field of the automatic regulator motor, and brings the left hand field into service, causing the automatic regulator to rotate contra-clock-wise, thus cutting out cells until the voltage reaches the desired point. By this means a constant E. M. F. is maintained on the lighting 'bus bars, and the cells are worked in parallel with both the lighting and elevator 'bus bars. 
It will be evident that the 15 end cells, or at any rate a portion of them when working in this manner, will become discharged through the day's run. After the batteries are cut off from the light, these end cells are re-charged as follows: Switch No. 23 is closed, thus throwing in the booster motor. As soon as the booster dynamo is brought up to speed, the underload switch is closed, and switch No. 22 closed upward, the operation then being as follows: From the positive brush of the generator end of the booster, which is producing energy at a low voltage, the current passes through the proper conductor to the centre of the automatic regulator; thence out through the regulator arm to segment No. 1, and through its proper connection to cell No. 1; thence through the first 15 cells to the wire leading off between the fifteenth and sixteenth cell. From this point it passes along the conductor, through switch No. 23 to the underload switch; and from the underload switch back to the negative side of the booster generator. By means of a field rheostat, located on the switchboard, the E. M. F. of the booster generator is regulated and adjusted to correspond to the number of end cells which are being charged.

To charge all the cells in series from one of the main generators, it is necessary to increase the E. M. F. a sufficient amount to overcome the total voltage of the cells. This is done by placing the generator portion of the booster or motor-generator in series with the main generator as follows: Switch No. 23 is closed, thus throwing in the booster motor and at the same time energizing the fields of the booster dynamo. The booster motor is now started by means of its rheostat and brought up to speed. Switch No. 22 is closed downward, the path of the current then being as follows: From positive lighting 'bus bar through switch 22, to the underload switch, thence to the negative brush of the booster dynamo, out through the positive brush to centre of the automatic regulator, through this arm to segment No. 1, and thence through suitable connection to cell No. 1; through the entire series of cells to the negative lead, thence through the recording ammeter and overload switch; back through switch 22 to the negative lighting 'bus bar. The operations for manipulating the entire plant being then as follows:-

To charge all the cells in series with the main generator by means of the booster: Open switches 16 and 17 and close switches 23 and 22 down. 


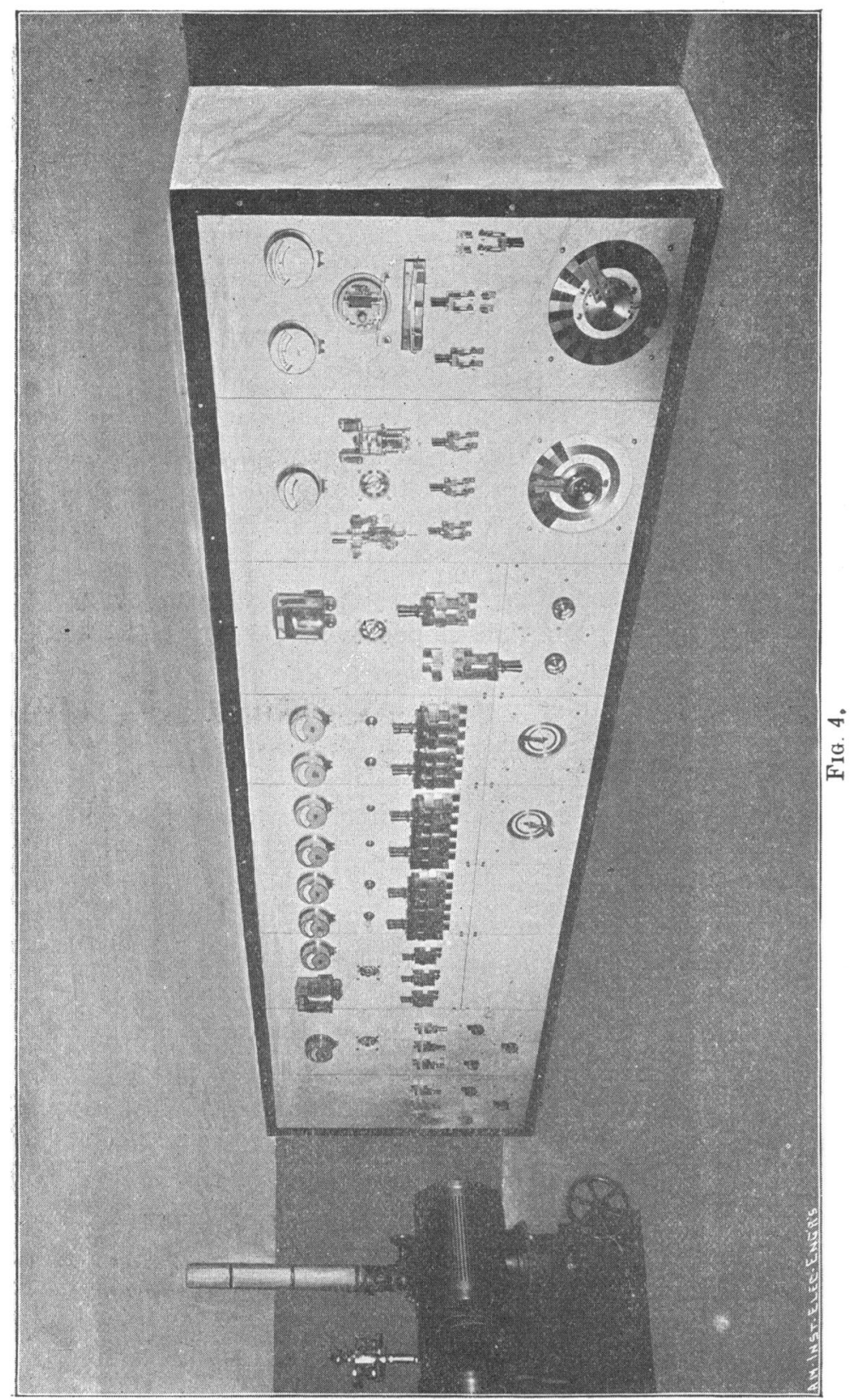


To charge all the batteries, except the end cells, at the same time operate light and elevators from one dynamo. Place hand regulator on segment 16 , connect whatever dynamo is in use to elevator 'bus bar by means of its elevator switch, either 11, 13 or 15 , in the $b$ position. Disconnect dynamo from lighting 'bus bars by opening its corresponding switch, either 10,12 or 14, and see that switches 22 and 23 are open, and that switches 16 and 17 are closed, the latter in the $a$ position.

To charge end cells with booster dynamo:-Place automatic regulator on segment No. 1, see that switch No. 16 is open, and close switches 23 and 22 up.

To place elevators, batteries and one of the generators in parallel, close the corresponding generator switch to the $b$ position, and close switch 17 to the $a$ position, if desired to run through the hand regulator, and to the $b$ position if desired to operate through the automatic, but if placed in the $b$ position, see that switch 16 is open.

To discharge the batteries with the generators shut down, operate as follows: On lights, open switches No. 22 and 23 , and close switch 16 . On elevators, close switch 17 to the $a$ position. To operate lights and elevators, see that switches No. 22 and 23 are open, and close switches 16 and 17 , the latter to the $b$ position.

Fig. 4 shows the elevation of this switchboard, and from it the position of the instruments shown on the diagram can be easily located.

The method of connecting the engines and generators is shown in Fig. 5, and represents a system planned by the writer, which enables a direct coupled plant to be so built as to have the advantage of an independent unit direct coupled plant, when operating under normal conditions, and all the flexibility of a belted plant in case of accident to any particular part of the plant. The cut shows the plan, elevation and section. It will be noticed that at present there are but two generators and two engines; but when extensions are needed, the right hand engine will be disconnected from its present dynamo, and moved to the right a sufficient distance to allow the placing of an engine of double its capacity in the same position it now occupies, and two generators between the middle engine and the right hand engine, thus making a plant with three engine units and four generator units, all four of which are available from the middle engine, 
and two of which are available from each of the outside engines. Referring to the sectional view, a $a$ represents the ends of the engine shafts which carry disks $\mathrm{\text { }} h$. The generators are mounted upon hollow sleeves or quills, which are supported in independent bearings, $\mathrm{P} \mathbf{P}$ and $p p$. The ends of these quills are enlarged to form flanges corresponding in diameter and thickness to the engine flanges. Between engine shafts a $a$ extends an
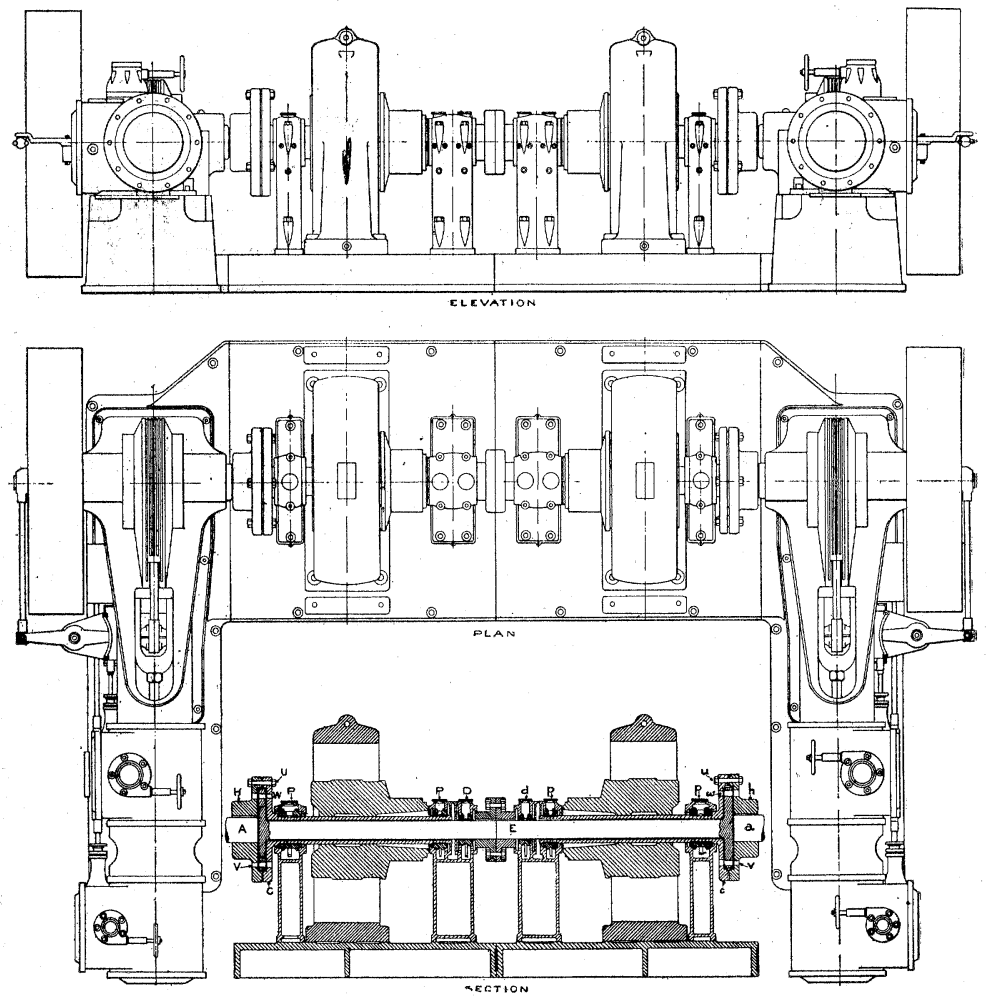

Fig. 5.

auxiliary shaft, $\mathrm{E}$ (coupled at its centre, in this case, to permit half of the plant being put in operation before the other half is ready), and carried in independent bearings, $\mathrm{D} d$. This shaft, $\mathrm{E}$, carries at each end circular disks, which in this case are forged solid with the shaft. Under normal conditions shaft $\mathrm{E}$ does not revolve, but lies passive in bearings $\mathrm{D} d$, and the engines drive the generators direct coupled, by inserting the bolts $\mathrm{v} u$, three of which, spaced $120^{\circ}$ apart, are used in each coupling. It is now evident 
that each engine is operating an independent unit direct coupled generator without revolving any more shafting or machinery than is usual in ordinary independent unit direct coupled plants, inasmuch as the quills which surround the auxiliary shaft $\mathrm{E}$ do not come in contact with it, but have a clearance of one-quarter of an inch all around it. If from any cause it becomes desirable to drive the left hand generator from the right hand engine, it is done as follows: In the openings $v$, three of which are provided $120^{\circ}$ apart, are placed taper bolts which couple the auxiliary shaft $\mathrm{E}$ solidly on the engine shaft $a$ by means of disk $h$. Taper bolts are also placed in spaces w, which couples shaft $\mathrm{E}$ to the quill of the left hand generator. By removing bolts $v$, which disconnect the left hand generator from the left hand engine, the left hand generator can now be driven from the right hand engine, and the right hand generator continues in operation from the same engine, if desired. By removing $u$, the right hand generator becomes disconnected from the right hand engine, and the left hand generator is being driven from the right hand engine. In the same manner the right hand generator can be driven from the left hand engine, or both generators from either one of the engines. By using compound engines, so designed that by working high pressure steam in the low pressure cylinder, one engine can be made to double its power for a few hours. The plant has thus the total generator capacity available at all times, and allows one engine to be in reserve for repairs, thus doing away with the investment of the third unit, which is usually carried in such plants for safety. The system, when used without the battery auxiliary, instead of being provided with bolted connections as here shown, is provided with magnetic clutches, which permit the generators to be brought up to speed as motors, and thrown in connection with the engines without stopping either engine in use. This makes it possible to connect either generator with either engine without shutting down the plant in any part. With such an arrangement, with the engine and generators equal to the maximum eapacity of the plant, and battery auxiliary equal to one-third the capacity of the plant, any office building can be operated in the most economical manner, according to the writer's belief, for when the battery is in operating order, one unit in conjunction with the battery, handles the plant economically and satisfactorily, leaving one engine unit in reserve. In case the battery is out of service, both units can be 
operated until the battery is ready for service again, and during the light load period the battery auxiliary takes care of the entire service of the building, without the use of either the engine or generator units.

The engines are operated during the summer compound condensing, by using a cooling pan system and siphon condenser, as shown in section at the right hand of Fig. 1. With this arrangement the condensing water is cooled by means of the 72 " ventilating fan which is in operation during the entire 16-hour run of the plant, and is used for ventilating the building. It was thought advisable to utilize the air from this fan for cooling the water, inasmuch as the energy for driving the fan had to be produced, and utilizing the air from the fan would not entail any additional expenditure of energy upon the plant over that required under ordinary conditions. The condenser is placed near the ceiling of the boiler room and delivers into the standpipe extending downward into a pit about 35 feet. From the bottom of the pit a direct acting deep well pump lifts the water and delivers it to the cooling pans. From the cooling pans the water reaches through suitable piping the cistern shown on Fig. 1. From this cistern the injection pipe from the condenser leads. For this reason the plant will operate about six months of the year compound condensing, and during the balance of the year compound non-condensing, when the steam from the engines will be run into the mains of the building and used for steam heating.

Fig. 6 represents the load diagram of this plant. ${ }^{1}$ The parallelogram A, B, c, D, representing the total capacity in kilowatt hours of one of the generator units, assuming that the unit starts at seven o'clock A. M. and operates until eleven o'clock P. M. The line' $a, b, c, d, e, f, g, h, i, j, k, l, m$, represents the load line, or energy required by the building during the same period. That portion of the diagram shaded with lines inclining to the right at an angle of $45^{\circ}$ represents the amount of energy passing into the batteries, while the portion of the diagram represented by shade lines inclining to the left at an angle of $45^{\circ}$ represents the amount of energy delivered from the batteries. It will be noticed that from 11 P. м. until 7 A. M. the entire load of the plant is operated by the batteries alone. With this arrangement but two shifts of labor are required, one operating from 7 A. M. until 3 P. м., and the other from 3 р. м. until 11 P. M. From 11 г. м.

1. For this diagram see p. 648 , vol. xii. 
until morning during the winter the watchman acts as fireman for the boilers to maintain the steam heat in the building. This diagram having previously been illustrated in the TransaOtions of the InstituTe November 1895, it will not further be described here, except to state that the various lines shown on the diagram represent the loads of the different motors, elevators, etc., and the periods during which they operate. The writer hopes in the future to present to the Institute a new diagram representing the actual load lines of the plant, compiled from statistics covering its operation for a considerable length of time, and it will then be interesting to compare the actual diagram with this one which was prepared before starting to design the plant.

\section{Discussion.}

Mr. WoLCotT :-I would like to ask Mr. Arnold whether it would be cheaper to use some gas now in that building or to use the battery a little more and dispense with the gas. He says some gas is used, as I understand him. I notice that there is a sudden drop in the load at 5:30 P. M. when the gas is turned on, and that allows the surplus current to go into the battery. If that gas were not used, the diagram would be of a considerably different shape.

Mr. ARNoLD :-This diagram was prepared in my office before the method of re-constructing the plant was decided upon, and the various lines represent the different motors, elevators, etc., as we supposed they would operate in practice. The point marked "gas turned on" is the time they turn the gas on now,-not what it will be in operation, because we propose to turn the gas off entirely. This diagram was prepared over a year ago. In all probability, within six months from now I will be able to give you a diagram showing what the actual load line of the plant is.

Mr. J. W. Lieb, JR :-I would like to ask Mr. Arnold why it is that in the plant he describes the peak of the load occurs between 11 A. M. and 1 P. M.

Mr. Arnold:--That is the time when the people connected with the Chicago Board of Trade are most excited. The Board opens at 9.30 o'clock in the morning. At 12.30 they go to their offices and figure up what they have made or lost, consequently the office lights are used most at this time, and some of the motors shown running at this particular period are shut off at a later period, which also accounts for a part of the load.

Mr. RIEs :- I would like to ask Mr. Arnold to explain a little more fully the precise conditions under which-referring to Fig. 5-one steam engine is cut off and the other one is connected to the intermediate shaft to drive both dynamos. It would seem that this arrangement would not prove very practicable 